THE comparatively few accounts of uveitis in children all agree that it is uncommon (Table I). This report concerns 150 cases of uveitis starting before the age of 16 years. Most of the children were below this age when first seen; although 5 were aged between 16 and 20 and 3 were over 20 , there was good documentary evidence that the uveitis had started before the age of 16 . The 150 cases represent 5 per cent. of the total of 2,890 referred to the Uveitis Clinic of the Institute of Ophthalmology in the period from 1956 to 1964.

The proportion of children under 15 years of age in the population of England and Wales in 1951 was over 20 per cent., so that there are fewer cases of uveitis in children than would be expected from the age structure of the population. It is interesting that Davis (1953) found a similar proportion of cases of uveitis in children-21 out of a total of 400-and Kimura, Hogan, and Thygeson (1954) $5 \cdot 8$ per cent. of 810 cases of uveitis.

TABLE I

INCIDENCE OF UVEITIS IN CHILDREN

\begin{tabular}{l|c|c|c|c}
\hline \multicolumn{1}{c|}{ Author } & $\begin{array}{c}\text { Total in } \\
\text { Series }\end{array}$ & $\begin{array}{c}\text { No. of } \\
\text { Children }\end{array}$ & $\begin{array}{c}\text { Age Group } \\
\text { (years) }\end{array}$ & $\begin{array}{c}\text { Percentage } \\
\text { of Total }\end{array}$ \\
\cline { 2 - 2 } Blegvad (1941) & 896 & 20 & Under 15 & $2 \cdot 2$ \\
Guyton and Woods (1941) & 562 & 7 & Under 10 & $1 \cdot 3$ \\
Marchesani (1949) & 451 & 59 & $10-19$ & $8 \cdot 8$ \\
Davis (1953) & 400 & 21 & Under 15 & $3 \cdot 7$ \\
Kimura, Hogan, and Thygeson (1954) & 810 & 47 & Under 16 & $5 \cdot 0$ \\
Bennett (1955) & 332 & 7 & Under 15 & $5 \cdot 8$ \\
Perkins (1961) & 1,718 & 40 & Under 11 & $2 \cdot 1$ \\
& & 169 & $11-20$ & $9 \cdot 3$ \\
\hline
\end{tabular}

The cases inevitably represent a selected group, as only those which were more severe and chronic are likely to have been referred for investigation. The methods of investigation used in the clinic have been described previously (Perkins, 1961).

* Received for publication July 22, 1965. 


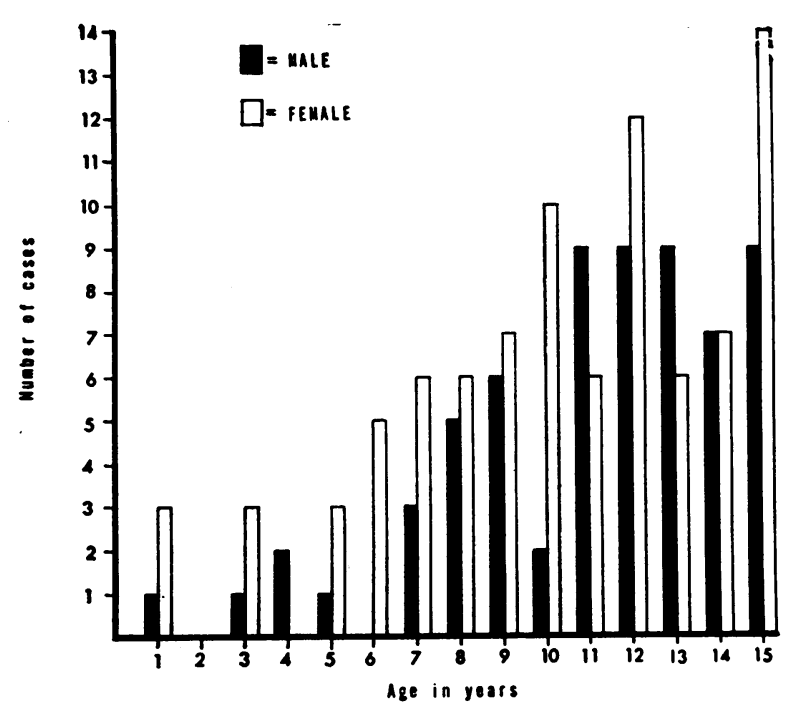

FIGURE.-Sex and age incidence in 150 cases of uveitis in children.

TABLE II

TyPe of UVEITIS IN A SERIES OF 150 ChILDREN

\begin{tabular}{l|c|c}
\hline Type of Uveitis & No. of Cases & Percentage of all Cases \\
\hline Anterior acute & 34 & 22.6 \\
Anterior chronic & 40 & 26.6 \\
\hline Posterior acute & 29 & $19 \cdot 3$ \\
Posterior chronic & 30 & $20 \cdot 0$ \\
\hline Generalized acute & 2 & $1 \cdot 3$ \\
Generalized chronic & 15 & $10 \cdot 0$ \\
\hline Total & 150 & \\
\hline
\end{tabular}

The sex and age distribution of the series is shown in the histogram (see Figure). Girls predominate in a ratio of 86 to 64 , and in both sexes the prevalence increases with age. The incidence of the clinical types of uveitis (Table II) shows that chronic uveitis is more common than acute uveitis in this series. This distribution is the reverse of that found in uveitis in the adult. In a series of 1,718 cases of uveitis of all ages (which includes some of the children reported on here), acute cases accounted for three-quarters of the total (Perkins, 1961). This difference is highly significant in statistical terms (Table III). Other authors have also found that uveitis in children tends to be chronic rather than acute, and although it is possible that mild acute attacks of short duration are likely to be overlooked or diagnosed as conjunctivitis in children, the difference may well be real.

If the clinical categories are considered with the sex of the patients (Table IV), a marked excess of girls with chronic anterior uveitis is apparent. The difference between the sex distribution in this group and the chronic posterior and generalized groups together is statistically significant $\left(\chi^{2}=14 ; P<0.01\right)$. 
TABLE III

COMPARISON OF INCIDENCE OF ACUTE AND CHRONIC UveITIS

\begin{tabular}{c|c|c}
\hline Uveitis & Children & All Ages \\
\hline Acute cases & 65 & 1,305 \\
Chronic cases & 85 & 413 \\
\hline Total & 150 & 1,718 \\
\hline
\end{tabular}

$\chi^{2}=>50 ; P<0.0$
TABLE IV

Sex Distribution of Uveitis in Children

\begin{tabular}{|c|c|c|c|}
\hline Type of Uveitis & Male & Female & $\begin{array}{l}\text { Female } \\
\text { per cent. }\end{array}$ \\
\hline $\begin{array}{l}\text { Anterior acute } \\
\text { Anterior chronic }\end{array}$ & $\begin{array}{r}19 \\
5\end{array}$ & $\begin{array}{l}15 \\
35\end{array}$ & $\begin{array}{l}44 \cdot 1 \\
87 \cdot 5\end{array}$ \\
\hline $\begin{array}{l}\text { Posterior acute } \\
\text { Posterior chronic }\end{array}$ & $\begin{array}{l}15 \\
14\end{array}$ & $\begin{array}{l}14 \\
16\end{array}$ & $\begin{array}{l}48 \cdot 3 \\
53 \cdot 3\end{array}$ \\
\hline $\begin{array}{l}\text { Generalized acute } \\
\text { Generalized chronic }\end{array}$ & $\overline{11}$ & $\begin{array}{l}2 \\
4\end{array}$ & $\begin{array}{c}(100 \cdot 0) \\
26 \cdot 6\end{array}$ \\
\hline
\end{tabular}

Anterior chronic versus other chronic cases: $\chi^{2}=14 ; \mathrm{P}<0.01$

This series of cases of uveitis in children shows a higher proportion (39.3 per cent.) of cases of posterior uveitis than that found in a series of all ages (19.2 per cent.; Perkins, 1961). This is partly due to the comparatively high incidence ( 20 per cent.) of chronic posterior uveitis in the children, compared with only 4 per cent. in a series of all age-groups.

\section{Acute Anterior Uveitis}

Thirty-four children, 19 boys and 15 girls, were diagnosed as having acute anterior uveitis, and this group of cases accounted for 22.6 per cent. of the total of 150. This is a smaller proportion than is found in adults with uveitis, but otherwise the pattern resembled the condition as seen in adults, including the failure to find any definite aetiology in the majority of cases.

Uveitis secondary to herpetic keratitis occurred in 5 cases, in 3 tuberculosis was suspected, 2 were probably traumatic in origin, and some evidence of recent infection in teeth and tonsils, for instance, was noted in 6 cases. Case 58 in Table V had signs and symptoms suggesting juvenile rheumatoid arthritis.

On the whole, the condition responded well to treatment, although systemic steroids were required in a few cases, and recurrences have been observed in at least six.

The clinical features are summarized in Table V. It will be noted that most of the cases occurred in children over the age of 7, the mean age of onset in the girls being 10.5 and in the boys 11.8 years. It is unlikely that acute anterior uveitis in children differs greatly, except in overall incidence, from that seen in adults.

\section{Chronic Anterior Uveitis}

There were 40 children in this diagnostic category and the cases are summarized in Table VI. The aetiology in 2 patients, one boy and one girl, was thought to be tuberculosis, in 2 sarcoidosis, and 4 had heterochromic uveitis. Two patients (Cases 128 and 82 in Table VI) had marked anterior vitreous opacities and may have had peripheral choroiditis, although no note was made of fundus changes. Case 119 was a baby with microphthalmos and a chronic uveitis which may have been present since birth. The remaining 29 exhibited a syndrome possibly confined to children: 
TABle V

ACUTE ANTERIOR UVEITIS

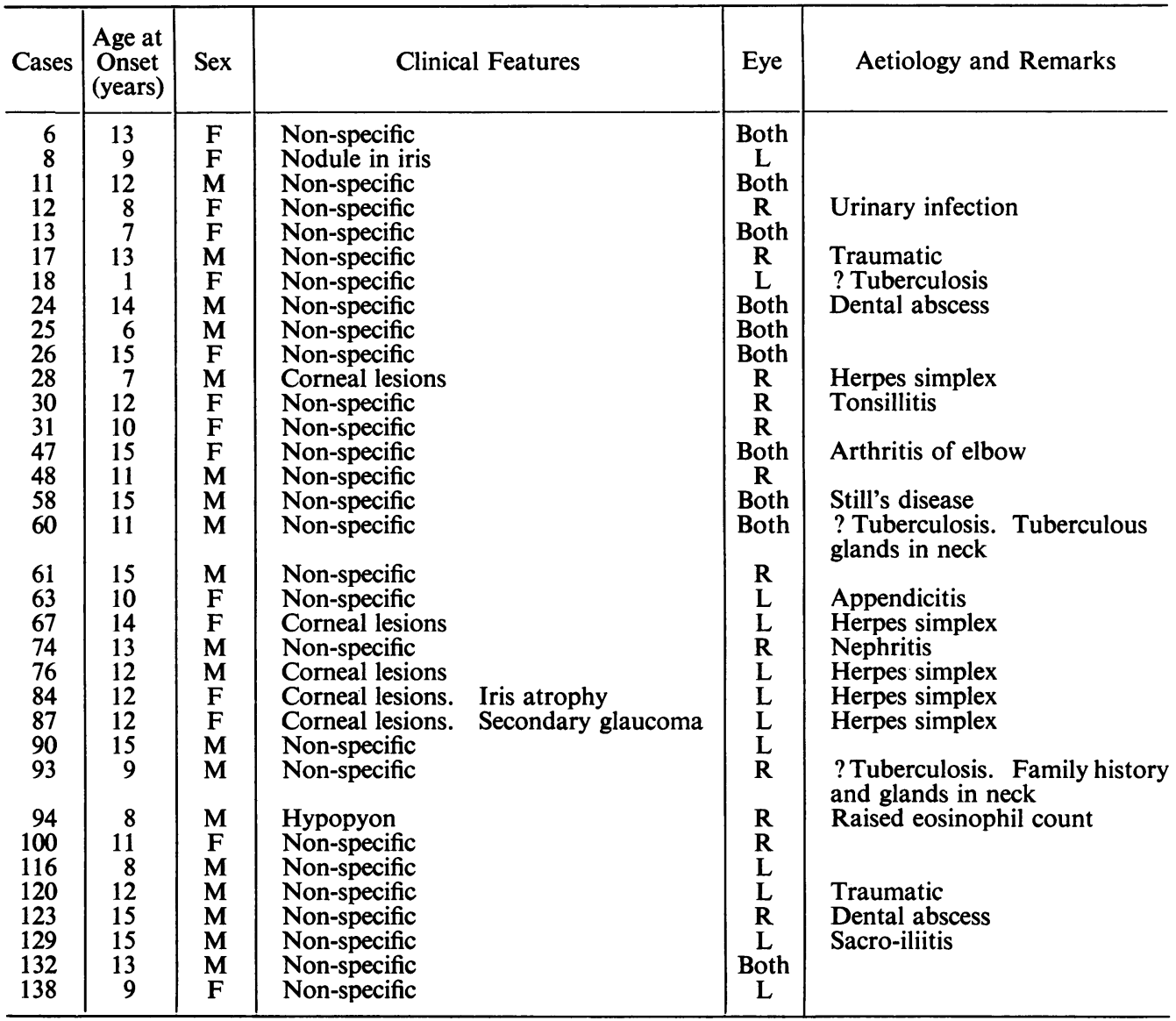

a chronic iridocyclitis with posterior synechiae, band-shaped degeneration of the cornea, and secondary lens changes. Six out of the total of 40 cases of chronic anterior uveitis had all these features, a further 10 had a chronic iridocyclitis with corneal changes but no secondary cataract, and 13 presented with similar uveal changes but no abnormality of the cornea or lens.

This type of uveitis has been described in association with Still's disease, but that it can occur without evidence of rheumatic disease seems certain (Davis, 1953; Unger and Schomerus, 1954; Smiley, May, and Bywaters, 1957), and in this series only two of the patients had physical signs of joint disease, a further five giving a history of pain in one or more joints. Only two of those in whom there was any evidence of rheumatism had band degeneration and lens changes. In the four others with the complete syndrome and the ten with corneal changes and iridocyclitis there was no history of joint disease.

It is possible, of course, that the joint manifestations may occur at a later date, but two of the patients were free from joint disease many years (twenty-nine in one 
TABLE VI

Chronic ANTERIOR Uveitis

\begin{tabular}{|c|c|c|c|c|c|}
\hline Cases & $\begin{array}{c}\text { Age at } \\
\text { Onset } \\
\text { (years) }\end{array}$ & Sex & Clinical Features & Eye & Remarks \\
\hline 75 & 14 & M & Nodules in iris & $\mathbf{L}$ & ? Tuberculosis \\
\hline 39 & 7 & $\mathbf{F}$ & Severe iritis & Both & ? Tuberculosis \\
\hline 78 & 10 & $\mathbf{M}$ & Typical heterochromic uveitis & $\mathbf{R}$ & \\
\hline 83 & 12 & $\mathrm{~F}$ & Typical heterochromic uveitis & $\mathbf{R}$ & \\
\hline 15 & 15 & $\mathbf{F}$ & Typical heterochromic uveitis & $\mathbf{R}$ & \\
\hline 51 & 15 & $\mathbf{F}$ & Typical heterochromic uveitis & $?$ & \\
\hline 145 & 13 & $\mathbf{F}$ & Kerato-uveitis & Both & ? Sarcoidosis \\
\hline 144 & 8 & $\mathbf{M}$ & Non-specific & Both & ? Sarcoidosis \\
\hline 128 & 15 & $\mathbf{F}$ & Vitreous opacities + & $\mathbf{L}$ & ? Peripheral choroiditis \\
\hline 119 & 1 & $\mathbf{F}$ & Microphthalmos & $\mathbf{L}$ & Congenital uveitis \\
\hline 32 & 9 & $\mathbf{F}$ & Band opacity. Lens changes & Both & Rheumatic history \\
\hline 117 & 14 & $\mathrm{~F}$ & Band opacity. Lens changes & $\mathbf{R}$ & Rheumatic history \\
\hline 133 & 5 & $\mathbf{F}$ & Band opacity. Lens changes & $\mathbf{R}$ & \\
\hline 20 & 4 & $\mathbf{F}$ & Band opacity. Lens changes & Both & \\
\hline 66 & 6 & $\mathbf{F}$ & Band opacity. Lens changes & Both & \\
\hline 37 & 6 & $\mathbf{F}$ & Band opacity. Lens changes & Both & \\
\hline 7 & 14 & $\mathbf{F}$ & Band opacity & Both & \\
\hline 147 & 9 & $\mathbf{F}$ & Band opacity & Both & \\
\hline 111 & 6 & $\mathbf{F}$ & Band opacity & Both & \\
\hline 40 & 4 & $\mathbf{F}$ & Band opacity & Both & \\
\hline 86 & 6 & $\mathbf{F}$ & Band opacity & Both & \\
\hline 105 & 6 & F & Band opacity & Both & \\
\hline 23 & 8 & $\mathbf{F}$ & Band opacity & Both & \\
\hline 106 & 7 & $\mathbf{F}$ & Band opacity & Both & \\
\hline 50 & 11 & $\mathbf{F}$ & Band opacity & Both & \\
\hline 118 & 10 & $\mathbf{F}$ & Band opacity & Both & \\
\hline 71 & 15 & $\mathbf{F}$ & Non-specific & Both & \\
\hline 1 & 14 & $\mathbf{F}$ & Non-specific & Both & \\
\hline 9 & 11 & $\mathbf{F}$ & Non-specific & Both & \\
\hline 82 & 13 & $\mathbf{F}$ & Vitreous opacities & $\mathbf{R}$ & Eosinophils 2,000/c. mm. \\
\hline 109 & 5 & F & Non-specific & Both & \\
\hline 148 & 3 & $\mathbf{F}$ & Non-specific & Both & \\
\hline 114 & 12 & $\mathbf{M}$ & Non-specific & Both & Developed polyarthritis later \\
\hline 41 & 3 & $\mathbf{F}$ & Non-specific & Both & \\
\hline 96 & 12 & $\mathbf{F}$ & Non-specific & $\mathbf{R}$ & \\
\hline 121 & 15 & $\mathbf{F}$ & Non-specific & Both & \\
\hline 98 & 10 & $\mathbf{F}$ & Non-specific & $\mathbf{L}$ & History of pain in knees \\
\hline 110 & 6 & $\mathbf{F}$ & Non-specific & Both & History of pain in knees \\
\hline 34 & 7 & M & Non-specific & Both & History of pain in ankle \\
\hline 33 & 15 & $\mathbf{F}$ & Non-specific & Both & History of muscular rheumatism \\
\hline
\end{tabular}

case and eighteen in the other) after the onset of the uveitis, and 18 replies to a questionnaire sent to the patients' doctors revealed that only one patient had subsequently developed arthritis. This was Case 114 (Table VI), one of the few boys in this group, who had had attacks of arthritis in an ankle eighteen months and two and a half years after the onset of uveitis and then, three years later, developed a polyarthritis. The mean period of follow-up for these 18 patients was over seven years (minimum three years, maximum thirteen years).

It is likely, therefore, that band degeneration is independent of a rheumatic aetiology and is associated only with the uveitis which may or may not be linked with joint disease. Band-shaped degeneration of the cornea was seen in one case of sympathetic ophthalmitis.

The figures suggest that the band degeneration occurs more frequently in the 
younger children. The mean age of onset of the uveitis in the children with banddegeneration was 7.9 years and the mean age in those without band-degeneration was 10.4 years. In Vesterdal and Sury's (1950) series of cases of rheumatoid arthritis there were 21 with band-degeneration, the mean age at onset (excluding those where this was doubtful) being 5 years, and 10 cases without corneal changes with a mean age of 11 years. In the present series there was also some correlation with the period of activity, the corneal changes being more frequent in cases in which the uveitis was more prolonged.

Table VI also shows the marked preponderance of girls with chronic anterior uveitis. In the group with evidence of joint disease the sex ratio was 5 females to 2 males, which corresponds with Vesterdal and Sury's (1950) figures of 23 to 11 and the similar ratio of 22 females to 9 males which the same authors found in a review of the literature.

In the present series all but one of the 24 patients with chronic anterior uveitis without a history of rheumatism or other aetiology were girls. This is a surprising finding and can hardly be a chance association. In the series of children with uveitis described by Kimura, Hogan, and Thygeson (1954) there were 3 patients with chronic iridocyclitis, all of whom were girls, and 15 out of 19 with iridocyclitis with band-degeneration described by Unger and Schomerus (1954) were also girls.

I know of no aetiological factor likely to be involved in these children which shows such a marked difference in sex incidence. Urinary infections are more common in girls than in boys, but evidence of such infection was only found in one case (Case 133, Table VI). Investigations revealed no active systemic disease in the other cases, but a raised white blood cell count was reported in 7 ; in 3 cases this may have been the result of steroid therapy. One (Case 82) had an unexplained eosinophil count of $2,000 / \mathrm{c} . \mathrm{mm}$; examination of the stools for ova and parasites was negative. Only one eye was affected, and although no fundus lesions were seen these may have been obscured by the dense vitreous opacities. In retrospect, this could have been an infestation with Toxocara canis, and is included in the discussion of this condition later.

Cases 147 and 148 are of some interest, as they are sisters. One, aged 9, was referred from school because of defective vision; examination showed a bilateral chronic anterior uveitis with early band-shaped degeneration of the cornea. The other, aged 3, had no visual symptoms, but she also was found to have a mild anterior uveitis in both eyes, without band-shaped opacity of the cornea. The elder sister had been treated for epilepsy and the younger child was backward in talking. Medical examination was negative and the only abnormality found was in the blood counts, which were as follows:

Elder sister (Case 147, Table VI), aged 9: Total white blood count, 12,000/c. mm. Polymorphs: neutrophils, 4,800; eosinophils, 600; basophils, none; lymphocytes, 6,000; monocytes, 600 .

Younger sister (Case 148, Table VI), aged 3: Total white blood count, 11,000/c. mm. Polymorphs: neutrophils, 3,300; eosinophils, 110; basophils, none; lymphocytes, 6,600; monocytes, 990 .

A familial incidence of uveitis is very rare in my experience and suggests either a common infective agent or some hereditary condition. The toxoplasma dye test 
was negative in both children and there was no history of recent infective disease or febrile illness. The fundi were normal and the electro-oculogram was normal in both children and in the mother. The elder sister had had "fluid on the knee" during the previous year, which was thought to have followed a fall. The condition of both children was essentially the same three months later in spite of treatment with local steroids.

\section{Acute Posterior Uveitis}

This group comprised 29 children, 15 boys and 14 girls, representing $19 \cdot 3$ per cent. of the whole series. The condition was characterized by discrete focal chorioretinal lesions, some inactive and discovered accidentally, others showing a recurrence of activity near an old lesion and a few showing an active chorio-retinal lesion but without scars of previous lesions. As so many of the patients had evidence of previous lesions but gave no definite history of symptoms, it is not possible to assess the age of onset of the condition accurately. The mean ages when first seen were: boys 11.4 years and girls 11.3 years.

The most striking feature of this group of cases is the fact that all of them had positive toxoplasma dye tests, compared with only 44 per cent. of the remaining 103 children in whom this test was done (Table VII).

Table VIII compares the dye test results in acute posterior cases with those of the cases of anterior uveitis (acute and chronic), in which toxoplasmosis is unlikely to be an aetiological factor.

The group of generalized chronic cases had the next highest proportion of positive dye tests, and it is probable that two of these cases were toxoplasmic. The height of the dye test titres in the diagnostic groups is shown in Table IX.

TABLE VII

Dye Test Results in Acute Posterior UVEITIS IN CHILDREN

\begin{tabular}{l|c|c|c}
\hline Type of Uveitis & $\begin{array}{c}\text { No. with } \\
\text { Positive } \\
\text { Dye Test }\end{array}$ & $\begin{array}{c}\text { No. with } \\
\text { Negative } \\
\text { Dye Test }\end{array}$ & Total \\
\hline $\begin{array}{l}\text { Acute posterior } \\
\text { All other cases }\end{array}$ & 29 & $\overline{57}$ & $\begin{array}{r}29 \\
103\end{array}$ \\
\hline
\end{tabular}

$\chi^{2}=23 ; \mathrm{P}<0.01$
TABLE VIII

Dye Test Results in Acute Posterior UveITIS AND ACUTE ANTERIOR UveITIS

\begin{tabular}{l|c|c|c}
\hline Type of Uveitis & $\begin{array}{c}\text { No. with } \\
\text { Positive } \\
\text { Dye Test }\end{array}$ & $\begin{array}{c}\text { No. with } \\
\text { Negative } \\
\text { Dye Test }\end{array}$ & Total \\
\hline $\begin{array}{c}\text { Acute posterior } \\
\text { Acute anterior }\end{array}$ & 29 & $\overline{38}$ & 29 \\
\hline$\chi^{2}=19 ; \mathrm{P}<0.01$ &
\end{tabular}

$\chi^{2}=19 ; \mathrm{P}<0.01$

TABLE IX

Dye Test Results in all TyPes of Uveitis

\begin{tabular}{l|c|c|c|c|c}
\hline \multicolumn{1}{c|}{ Type of Uveitis } & Negative & $\begin{array}{c}\text { Positive } \\
1: 4-1: 32\end{array}$ & $\begin{array}{c}\text { Positive } \\
>1: 32\end{array}$ & $\begin{array}{c}\text { Total } \\
\text { Positive }\end{array}$ & $\begin{array}{c}\text { Mean } \\
\text { Titre }\end{array}$ \\
\hline $\begin{array}{l}\text { Anterior acute } \\
\text { Anterior chronic }\end{array}$ & 16 & 10 & 4 & 14 & $1: 28$ \\
\hline $\begin{array}{l}\text { Posterior acute } \\
\text { Posterior chronic }\end{array}$ & $\overline{15}$ & 10 & 4 & 14 & $1: 30 \cdot 5$ \\
\hline $\begin{array}{l}\text { Generalized acute } \\
\text { Generalized chronic }\end{array}$ & $\overline{4}$ & $\overline{4}$ & $\overline{4}$ & 29 & $1: 55$ \\
\hline
\end{tabular}


Two of the highest titres in the whole series of children $(1: 380$ and $1: 760)$ occurred in the generalized chronic group and account for the mean dye test titre being highest in these cases. The mean titre in the posterior acute cases is the next highest, but although toxoplasmosis was the most likely diagnosis in these cases two-thirds had dye test titres of $1: 32$ or less. Although Toxoplasma organisms have been recovered from patients with very low or even negative dye test titres (Hogan, Zweigart, and Lewis, 1958; Zscheile, 1964), many authorities are reluctant to diagnose a uveitis as toxoplasmic unless the dye test titre is $1: 64$ or more.

Certainly it would be surprising if an acquired infection with Toxoplasma severe enough to cause retinal lesions provoked such a low antibody response. However, a positive dye test is proof of previous infection and a low titre is most easily explained by postulating that the acute phase of the disease occurred some yearsperhaps many years-previously. The problem is to decide when the initial infection did take place. Very few patients with typical ocular lesions of toxoplasmosis give a history of recent systemic disease suggesting toxoplasmosis, although a few cases (Hogan, 1958; Perkins, 1961; Remky, 1962) have been reported. Similarly, systemic toxoplasmosis in the adult rarely gives rise to ocular lesions. If post-natally acquired toxoplasmosis is not associated with ocular lesions, it is surprising that such an infection should be followed years later by ocular disease without other evidence of systemic recurrence.

The one circumstance in which ocular lesions commonly occur in the course of a systemic infection is in the congenital disease, in which the infection is transmitted to the child in utero by the mother, who herself shows no overt evidence of infection. It seems likely, therefore, that the toxoplasmic lesions of children and young adults are recurrences of a congenitally acquired infection which was not sufficiently severe to arouse comment in the newborn infant.

Three patients (Cases 38, 54, and 113) in the present series (Table X) were found accidentally to have choroidal scars in the fundus without any activity and with no history of symptoms. Two children (Cases 49 and 108) were seen during the first three years of life, and in both of these the lesions were inactive, but attention had been drawn to the eyes because the lesions were at the macula and had therefore resulted in gross visual defect. If the lesion does not involve the macula and remains inactive no symptoms arise and the scar is discovered only during routine examination.

Those patients comprising the bulk of the remaining cases with active lesions were found on examination to have scars of previous lesions, usually adjacent to the active area. In only four (Cases $16,57,62$, and 68) was there any doubt as to the presence of a previous lesion, and it is possible that in these children the infection had been acquired recently. One of these (Case 16) had the highest dye test titre in the series of cases with acute posterior uveitis, $1: 290$ when seen. In three others (Cases 5, 36, and 81) there was a history of activity within the previous two years, and although the clinical signs suggested that some of the old scars seen had been present for much longer periods the possibility of an acquired infection in childhood remains.

In the remaining 22 cases all the evidence suggests that the old scars might have been present since birth. Four of these children had squints, and in an additional child the vision in the affected eye had always been poor. The scars in all these 
TABLE X

ACUTE POSTERIOR Uveitis

\begin{tabular}{|c|c|c|c|c|c|c|}
\hline Cases & $\begin{array}{c}\text { Age } \\
\text { when } \\
\text { Seen } \\
\text { (years) }\end{array}$ & Sex & Clinical Features & Eye & $\begin{array}{l}\text { Dye } \\
\text { Test } \\
\text { Titre }\end{array}$ & Remarks \\
\hline $\begin{array}{r}3 \\
4 \\
5 \\
10 \\
14 \\
16 \\
22 \\
36 \\
38 \\
42 \\
43 \\
49 \\
52 \\
53 \\
54 \\
56 \\
57 \\
62 \\
64 \\
65 \\
68 \\
81 \\
88 \\
108 \\
113 \\
122 \\
139 \\
141 \\
143\end{array}$ & $\begin{array}{r}10 \\
9 \\
15 \\
12 \\
9 \\
12 \\
15 \\
13 \\
11 \\
14 \\
15 \\
3 \\
13 \\
8 \\
10 \\
9 \\
14 \\
10 \\
13 \\
13 \\
14 \\
13 \\
12 \\
1 \\
8 \\
12 \\
13 \\
14 \\
14\end{array}$ & $\begin{array}{l}M \\
M \\
F \\
F \\
M \\
F \\
M \\
F \\
F \\
F \\
M \\
F \\
F \\
M \\
M \\
F \\
F \\
F \\
M \\
M \\
M \\
F \\
M \\
M \\
F \\
M \\
M \\
M \\
F\end{array}$ & $\begin{array}{l}\text { Old scar with recurrence } \\
\text { Old scars. Inactive } \\
\text { Recurrence R. Old scar L. } \\
\text { Recurrence R. Old scar L. } \\
\text { Old scars at macula } \\
\text { Active lesion. No old scar seen } \\
\text { Old scar upper nasal vessels } \\
\text { L. active. Old scar R. } \\
\text { Old scar. Inactive } \\
\text { Old scar with recurrence } \\
\text { Old scar with recurrence } \\
\text { Old scar with recurrence } \\
\text { Old scar. Inactive } \\
\text { Old scars at maculae } \\
\text { Old scar near disc } \\
\text { Old scar R. Active L. } \\
\text { Vitreous opacities. Scar seen later } \\
\text { Active lesion L. } \\
\text { Old scar with recurrence } \\
\text { Active lesions } \\
\text { Macular lesions, active } \\
\text { Old scar both. Active L. } \\
\text { Recurrence R. Microphthalmos L. } \\
\text { Old scars. Cerebral calcification } \\
\text { Old scar. Inactive } \\
\text { Old scars with recurrence } \\
\text { Recurrence R. Old scar L. } \\
\text { Old scars with recurrence } \\
\text { Old scar. Detached retina }\end{array}$ & $\begin{array}{c}\text { R } \\
\text { Both } \\
\text { Both } \\
\text { Both } \\
\text { L } \\
\text { R } \\
\text { L } \\
\text { Both } \\
\text { R } \\
\text { L } \\
\text { L } \\
\text { R } \\
\text { R } \\
\text { Both } \\
\text { L } \\
\text { Both } \\
\text { L } \\
\text { L } \\
\text { R } \\
\text { L } \\
\text { R } \\
\text { Both } \\
\text { Both } \\
\text { Both } \\
\text { L } \\
\text { R } \\
\text { Both } \\
\text { L } \\
\text { R }\end{array}$ & $\begin{array}{lll}1 & : 24 \\
1 & : 24 \\
1 & : 8 \\
1 & : 7 \\
1 & : 160 \\
1 & : 290 \\
1 & : 32 \\
1 & : 13 \\
1 & : 14 \\
1 & 11 \\
1 & 119 \\
1 & : 32 \\
1 & : 32 \\
1 & : 50 \\
1 & 4 \\
1 & : 280 \\
1 & : 8 \\
1 & : 84 \\
1 & : 8 \\
1: 16 \\
1: 50 \\
1: 26 \\
1: 28 \\
1: 36 \\
1: 54 \\
1: 200 \\
1: 8 \\
1: 8 \\
1: 4\end{array}$ & $\begin{array}{l}\text { Squint } \\
\text { Nystagmus since age of } 3 \mathrm{mths}\end{array}$ \\
\hline
\end{tabular}

cases consisted of atrophic areas with marked pigment accumulation. In only one patient (Case 143) were the appearances less typical; this was a child of 14 with degenerative myopia and a detachment of the retina in the right eye. There was a deeply pigmented lesion in the eye with the detachment which did not show the usual punched-out area of chorio-retinal atrophy, and may not have been toxoplasmic in origin. The dye test was positive only in a titre of $1: 4$.

Remky (1962) considers that the clinical appearances of the fundus lesions in acquired toxoplasmosis differ from those in the congenital disease. However, he includes cases of central serous retinopathy in his toxoplasmic cases on the grounds of a raised antibody level in the aqueous. No one has, to my knowledge, demonstrated Toxoplasma organisms in such cases. It is certainly true that the cases which are first recognized in adult life do not show the bilateral macular "rosettes" commonly seen in the congenital disease, the lesions usually being associated with the main retinal vessels or adjacent to the disc. The fact that the macula is not involved is the reason why the lesion is not noticed until a recurrence causes symptoms. A mild congenital infection may therefore result in atypical lesions away from the macula, cause no symptoms in the infant, and be recognized only when a recurrence occurs at a later age. 
Why the Toxoplasma organisms lie dormant for many years and then suddenly become active again is not known. The peak incidence of such recurrences occurs in the years of adolescence and early adult life and may be linked with the changes in hormonal balance which are occurring at this period. Trauma to the eye may occasionally play a part, and stress may be a factor. Pregnancy may be associated with reactivation of a lesion and $I$ have seen several patients in whom this has happened. Fears for the child have been expressed in this situation, but none of the infants has been affected. This supports the view that invasion of the foetus takes place only during the initial infection of the mother, before circulating antibodies appear. Once such antibodies are present in the circulation the risk of transplacental infection is negligible.

If the view that most cases of ocular toxoplasmosis in the child and young adult are recurrences of congenital infection is correct, it would account for much of the difficulty in determining the source of the infection. These patients do not give any particular history of contact with animal sources of infection and they do not show a greater incidence of contact with animals than patients with uveitis of other aetiology (Perkins, 1961). This anomaly is resolved if the infection occurred prenatally, and what is required is a careful study of the environment of the mother during pregnancy. Such information, however, is very difficult to obtain many years after the event.

It would also be interesting to know whether all the mothers of patients with toxoplasmic chorio-retinitis had positive dye tests. In the few cases in which, to my knowledge, this has been done the mother has also given a positive result. If the ocular lesions in children and young adults follow a post-natally acquired infection, there is little reason to suppose that the mothers of such patients would show an incidence of positive dye tests greater than that in the normal population. A positive result in the mother would not, of course, mean that the patient had acquired the disease pre-natally, but a negative result in the mother would be strongly suggestive of a post-natal infection. If the patient and the mother were living together it could be argued that the fact that both had a positive dye test might result from infection from a common source. A negative dye test in the mother would therefore be much more significant.

Four of the patients considered to have toxoplasmosis are known to have had further recurrences of activity since they were first seen in the Uveitis Clinic. One (Case 81, Table X) had received treatment with Daraprim, and one (Case 57) with spiramycin. Specific therapy therefore does not prevent recurrences, presumably because the encysted forms are resistant to these drugs.

\section{Chronic Posterior Uveitis}

Thirty cases, 14 male and 16 female, were included in this diagnostic category (Table XI). Eighteen of them presented with exudative lesions in the periphery of the fundus or protruding into the vitreous at the posterior pole, accompanied in the active stage of the disease by gross vitreous opacities. These eighteen cases show some clinical resemblance to two of those diagnosed as having chronic anterior uveitis and to five diagnosed as having chronic generalized uveitis. All twenty-five have therefore been grouped together and will be discussed later. 
TABLE XI

Chronic Posterior Uveitis

\begin{tabular}{|c|c|c|c|c|c|}
\hline Cases & $\begin{array}{l}\text { Age at } \\
\text { Onset } \\
\text { (years) }\end{array}$ & $\operatorname{Sex}$ & Clinical Features & Eye & Remarks \\
\hline $\begin{array}{r}2 \\
19 \\
21 \\
27 \\
29 \\
35 \\
44 \\
45 \\
46 \\
55 \\
59 \\
69 \\
70 \\
73 \\
79 \\
80 \\
89 \\
92 \\
95 \\
97 \\
101 \\
104 \\
115 \\
126 \\
130 \\
131 \\
134 \\
135 \\
136 \\
142\end{array}$ & $\begin{array}{r}11 \\
4 \\
6 \\
12 \\
11 \\
15 \\
12 \\
7 \\
5 \\
10 \\
15 \\
12 \\
10 \\
11 \\
9 \\
11 \\
7 \\
14 \\
14 \\
8 \\
6 \\
15 \\
10 \\
10 \\
10 \\
9 \\
9 \\
3 \\
9 \\
8\end{array}$ & $\begin{array}{l}\mathbf{M} \\
\mathbf{F} \\
\mathbf{F} \\
\mathbf{F} \\
\mathbf{M} \\
\mathbf{F} \\
\mathbf{M} \\
\mathbf{F} \\
\mathbf{F} \\
\mathbf{F} \\
\mathbf{M} \\
\mathbf{F} \\
\mathbf{F} \\
\mathbf{M} \\
\mathbf{M} \\
\mathbf{F} \\
\mathbf{M} \\
\mathbf{F} \\
\mathbf{F} \\
\mathbf{M} \\
\mathbf{F} \\
\mathbf{M} \\
\mathbf{F}\end{array}$ & $\begin{array}{l}\text { Vitreous opacities and macular oedema } \\
\text { Peripheral uveitis } \\
\text { Peripheral mass } \\
\text { Uveitis and papillitis } \\
\text { Peripheral uveitis } \\
\text { Uveitis with perivasculitis } \\
\text { Squint and choroiditis } \\
\text { Mass at disc with vitreous bands } \\
\text { Vitreous opacities }++ \\
\text { Organized vitreous bands } \\
\text { Perivasculitis } \\
\text { Peripheral uveitis } \\
\text { Peripheral uveitis } \\
\text { Disseminated choroiditis } \\
\text { Peripheral mass with vitreous bands } \\
\text { Uveitis and papillitis } \\
\text { Secondary cataract. Vitreous opacities } \\
\text { Retinal haemorrhages } \\
\text { Perivasculitis } \\
\text { Vitreous opacities } \\
\text { Peripheral uveitis } \\
\text { Perivasculitis } \\
\text { Perivasculitis } \\
\text { Raised lesion at macula } \\
\text { Raised lesion at macula } \\
\text { Vitreous opacities. Mass in periphery } \\
\text { Vitreous opacities. Mass in periphery } \\
\text { Granulomatous mass } \\
\text { Retinal fold, peripheral mass } \\
\text { Vitreous opacities. Mass in periphery }\end{array}$ & $\begin{array}{c}\text { L } \\
\mathbf{R} \\
\mathbf{L} \\
\text { Both } \\
\mathbf{L} \\
\mathbf{L} \\
\mathbf{R} \\
\mathbf{R} \\
\mathbf{L} \\
\mathbf{L} \\
\text { Both } \\
\text { Both } \\
\mathbf{L} \\
\text { Both } \\
\mathbf{R} \\
\text { Both } \\
\text { Both } \\
\mathbf{L} \\
\text { Both } \\
\text { Both } \\
\text { Both } \\
\mathbf{R} \\
\mathbf{L} \\
\mathbf{R} \\
\mathbf{R} \\
\mathbf{L} \\
\mathbf{L} \\
\mathbf{L} \\
\mathbf{L} \\
\mathbf{L}\end{array}$ & $\begin{array}{l}\text { ? Toxoplasmosis } \\
\text { ? Endophthalmitis } \\
\text { ? Eales's disease } \\
\text { Congenital syphilis } \\
\text { Urinary infection } \\
\text { ? Eales's disease } \\
\text { Severe facial herpes }\end{array}$ \\
\hline
\end{tabular}

Six cases diagnosed as having chronic posterior uveitis presented with perivascular retinal lesions, and probably fall into the category of Eales's disease. Two showed uveitis with swelling of the optic disc; one of these was thought to be due to sarcoidosis. One case of disseminated choroiditis occurred in a child with congenital syphilis and one case of focal choroiditis may have been toxoplasmic in origin.

\section{Peripheral Choroiditis and Toxocara canis (Table XII)}

Some of the patients with chronic uveitis, although this was diagnosed variously as chronic anterior, chronic posterior, and chronic generalized uveitis, seem in retrospect to form a relatively homogeneous group, characterized by dense vitreous opacities often completely obscuring the fundus but sometimes with visible lesions in the periphery. Although the aetiology is obscure in many cases, the lesions in some of them are characteristic of infestation with Toxocara canis, and it may be helpful to review these cases in more detail in an attempt to identify pathognomonic signs.

As none of the eyes was removed and examined pathologically, the evidence of Toxocara infestation is indirect. The best circumstantial evidence would be a history 


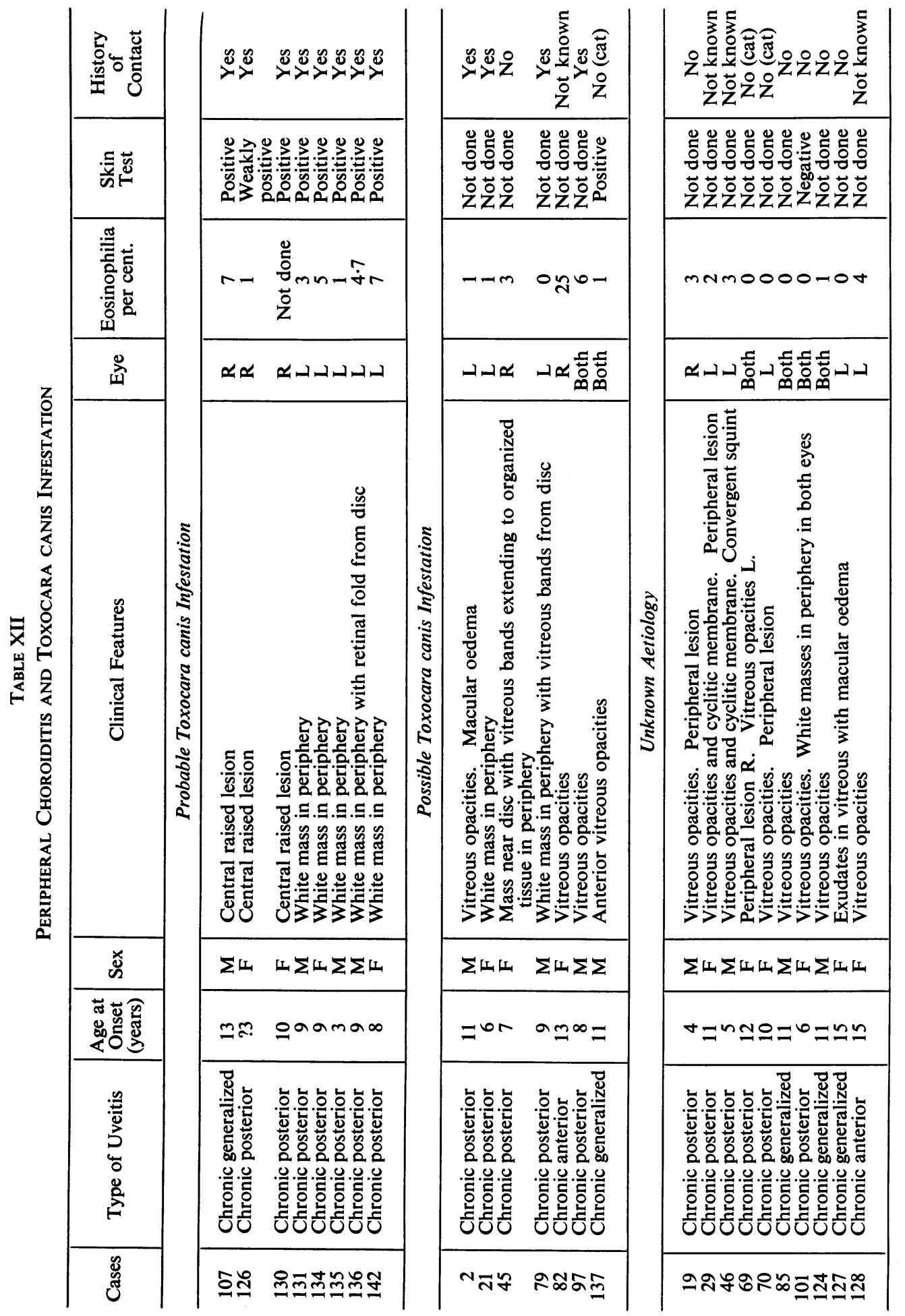


of contact with a dog, a granulomatous mass in the eye, eosinophilia, and a positive skin test (or serological test) for Toxocara-a combination found in Cases 107, 134, 136, and 142 (Table XII). Similar evidence, except for a lesser degree of eosinophilia ( 3 per cent. or less), was present in Cases $126,130,131$, and 135 . It is highly probable that all these cases were caused by Toxocara infestation. Case 126 was aged 10 years at the time of examination, but the history suggested that the condition had been present for many years.

Typical fundus lesions and a history of contact with dogs were present in two patients (Cases 21 and 79); in neither of these were skin tests done, nor was the eosinophil count raised. Case 137 presented with marked vitreous opacities and gave a positive toxocara skin test, although there was no history of contact with dogs. Cases 2 and 97 both gave a history of contact with dogs. Case 2 showed marked vitreous opacities with macular oedema, but no granulomatous mass was seen in the fundus and the eosinophil count was only 1 per cent. of the total white blood count. Case 97 had marked vitreous opacities in both eyes but no focal lesions could be seen. The eosinophil count was 624, 6 per cent. of the total white blood count. Skin tests were not done in these cases.

Three further patients, Cases 45, 69, and 101, showed rather similar fundus changes. Case 45 had a granulomatous mass near the disc with vitreous bands extending to organized tissue at the periphery of one eye. There was no history of contact with dogs; the toxocara skin test was not done, but the eosinophil count was 3 per cent. (138) of the total white blood count. Case 69 had extensive peripheral lesions in the inferior temporal area of the right fundus and gross vitreous opacities with no observable fundus lesions in the left eye. The toxocara skin test was not done and there was no history of contact with dogs, but the family kept a cat. Case 101 had a severe bilateral uveitis and developed organized white masses in the periphery of both fundi. The toxocara skin test was negative, no eosinophils were present in the blood, and there was no history of contact with dogs.

One other patient (Case 82), presenting with a marked vitreous haze in one eye which obscured details of the fundus, had a high eosinophil count of 2,000, 25 per cent. of the total white blood count. No cause for the eosinophilia was discovered, but at the time of examination Toxocara infestation was not considered as a possible aetiological factor and there was no inquiry as to contact with animals.

The remaining cases listed in Table XII were characterized clinically by dense vitreous opacities, sometimes with peripheral areas of choroiditis. None of them gave a history of contact with dogs, eosinophil counts were within normal limits, and toxocara skin tests were not done.

In Table XII the cases are divided into three groups: those probably due to Toxocara, those possibly due to Toxocara, and those of unknown aetiology. Those probably or possibly due to Toxocara tended to be younger and to have higher eosinophil counts, and in all except two the uveitis was unilateral, compared with the group of unknown aetiology in which the mean age was higher and the eosinophil count lower, and in which 4 out of 10 cases were of bilateral uveitis.

The toxocara skin test used in this series was that described and developed by Duguid (1961). The results so far have correlated well with pathological and clinical findings, but whether the test is specific for Toxocara canis has not been 
proved. A high eosinophil count is very suggestive of a parasitic infestation but may occur in other allergic conditions. A low count does not exclude Toxocara, as the primary infestation may have occurred some years previously or the infestation may be very light.

In summary, it may be said that.Toxocara infestation should be suspected in any child with white or grey lesions in the fundus which protrude into the vitreous either at the posterior pole or in the periphery. Some of the cases described by Schepens (1950) as peripheral choroiditis and by Welch, Maumenee, and Wahlen (1960) as pars planitis may well have fallen into this category, and Hogan (1965) has reported one typical case in which the eye was excised and the nematode discovered in an eosinophilic granuloma lying in the periphery of the retina. Hogan also pointed out that in his series of cases the condition had never spread to the other eye if one eye only was affected when the patient was first seen. Invasion of both eyes with Toxocara larvae is much less likely than invasion of one eye only, and it is likely that most cases of bilateral uveitis are due to some other cause as yet undiscovered. It is interesting to note that many of the reported cases of peripheral choroiditis or pars planitis have occurred in children, although adults are by no means immune. Unfortunately, Toxocara infestation has not been considered in the aetiology of the published cases.

Reliable serological tests for Toxocara infestation are not yet available. Wood, Ellison, Kelley, and Kaufman (1965) have described a haemagglutination test, but although higher titres were obtained with serum containing Toxocara antibodies the test also gives positive results with Ascaris. These authors' results do suggest that antibodies to Toxocara are not uncommon in children in Florida.

\section{Acute Generalized Uveitis}

Only two cases were diagnosed as having an acute generalized uveitis. One of these was a 3-month-old girl with an endophthalmitis. The other was a girl of 9 years with a history of sudden onset of blurring of vision and a red eye; she was found to have an anterior uveitis, a small focus of choroido-retinitis peripherally, and swelling of the optic disc. Investigations revealed a mild normochromic normocytic anaemia, with a rather low white blood count $(4,400 / \mathrm{c} . \mathrm{mm}$.) and a neutrophil count of 1,496 . No cause was found for the uveitis and the condition improved spontaneously over the next two months.

\section{Chronic Generalized Uveitis}

Characterized by a chronic uveitis involving the anterior and posterior segments, this was a rather mixed group and overlapped to some extent with cases in the chronic posterior and anterior groups. As will be seen from Table XIII, one case of definite peripheral choroiditis, three cases of uveitis with marked vitreous opacities, and one with a macular lesion, were similar to some of the cases diagnosed as having chronic posterior uveitis and have been discussed with them.

Case 125 (Table XIII) was probably one of congenital toxoplasmosis and had the highest dye test titre of all the children studied. Case 107 had a lesion typical of Toxocara canis infestation and had a positive skin test and eosinophilia. This 
TABLE XIII

Chronic Generalized Uveitis

\begin{tabular}{|c|c|c|c|c|c|}
\hline Cases & $\begin{array}{l}\text { Age at } \\
\text { Onset } \\
\text { (years) }\end{array}$ & Sex & Clinical Features & Eye & Remarks \\
\hline $\begin{array}{r}72 \\
77 \\
85 \\
91 \\
99 \\
102 \\
103\end{array}$ & $\begin{array}{r}12 \\
9 \\
11 \\
15 \\
6 \\
10 \\
15\end{array}$ & $\begin{array}{l}\text { M } \\
\mathbf{M} \\
\mathbf{M} \\
\mathbf{F} \\
\mathbf{M} \\
\mathbf{F} \\
\mathbf{F}\end{array}$ & $\begin{array}{l}\text { Uveitis and papillitis } \\
\text { Secondary cataract. Vitreous opacities } \\
\text { Vitreous opacities } \\
\text { Iris nodule. Secondary cataract } \\
\text { Chronic uveitis with poliosis and vitiligo } \\
\text { Bilateral uveitis following trauma } \\
\text { Uveitis and papillitis }\end{array}$ & $\begin{array}{l}\text { Both } \\
\text { L } \\
\text { Both } \\
\text { L } \\
\text { Both } \\
\text { Both } \\
\text { Both }\end{array}$ & $\begin{array}{l}\text { ? Sarcoidosis } \\
\text { See Table XII } \\
\text { Vogt-Koyanagi syndrome } \\
\text { Sympathetic ophthalmitis } \\
\text { Followed B.C.G. vaccin- }\end{array}$ \\
\hline $\begin{array}{l}107 \\
112 \\
124 \\
125\end{array}$ & $\begin{array}{c}13 \\
13 \\
11 \\
\text { ?Birth }\end{array}$ & $\begin{array}{l}\mathbf{M} \\
\mathbf{M} \\
\mathbf{M} \\
\mathbf{M}\end{array}$ & $\begin{array}{l}\text { Central raised lesion } \\
\text { Band opacity of cornea } \\
\text { Vitreous opacities } \\
\text { Large central scars L. Recurrence R. }\end{array}$ & $\begin{array}{l}\text { R } \\
\text { Both } \\
\text { Both } \\
\text { Both }\end{array}$ & $\begin{array}{l}\text { ation. } \\
\text { See Table XII } \\
\text { Sympathetic ophthalmitis } \\
\text { See Table XII } \\
\text { Congenital toxoplasmosis }\end{array}$ \\
\hline $\begin{array}{l}127 \\
137 \\
140 \\
146\end{array}$ & $\begin{array}{r}15 \\
11 \\
4 \\
4\end{array}$ & $\begin{array}{l}\mathbf{F} \\
\mathbf{M} \\
\mathbf{M} \\
\mathbf{M}\end{array}$ & $\begin{array}{l}\text { Peripheral choroiditis with macular oedema } \\
\text { Vitreous opacities } \\
\text { Chronic endophthalmitis } \\
\text { Uveitis and papillitis }\end{array}$ & $\begin{array}{c}\text { L } \\
\text { Both } \\
\mathbf{R} \\
\text { Both }\end{array}$ & $\begin{array}{l}\text { See Table XII } \\
\text { See Table XII } \\
\text { Confirmed pathologically }\end{array}$ \\
\hline
\end{tabular}

patient also had a dye test titre of $1: 380$. In three cases the uveitis was accompanied by swelling of the disc.

The one case of Vogt-Koyanagi's syndrome occurred in an Egyptian boy and was characterized by a chronic uveitis with diffuse fundus changes, poliosis, and vitiligo.

\section{Discussion}

It is clear from this review that uveitis in children shows a different pattern from that in adults. The acute anterior uveitis of a non-specific character which preponderates among adult patients is much less common in children. However, there are some distinctive types of uveitis among the children which are seen less often among adults. Chief among these is the chronic uveitis which may involve mainly the anterior segment or the ciliary body and periphery of the choroid. Those cases in which the inflammation is mainly anterior include some of juvenile rheumatoid arthritis, and although the ocular signs may precede the joint symptoms it is probable that most of these children will not develop rheumatism. The aetiology of the uveitis in those without rheumatism may, of course, be the same as that in the rheumatic disease, but the great preponderance of girls in this group suggests a different though unknown aetiology.

As might be expected, the most important aetiological factor in uveitis in children is toxoplasmosis, and it was thought to be the cause in 20.6 per cent. of the 150 children. In only a few of these was there evidence that the lesions were of recent origin; the majority presented with inactive scars or an active area of chorio-retinitis adjacent to an old focus, and this may well have been a recurrence of congenital infection. A squint, nystagmus, or a history of defective vision from an early age, made a diagnosis of congenital toxoplasmosis almost certain in 7 cases. Although the dye test was positive in all cases there were few with high titres, again suggesting that the initial infection had taken place many years previously. None of the 
patients gave a history of systemic disease consistent with toxoplasmosis except for one with definite congenital disease who had had fits as a child and showed cerebral calcification. Two other patients had a history of gastro-enteritis as babies and one was mentally retarded, although there was no definite evidence of cerebral toxoplasmosis.

If, as I believe, most cases of toxoplasmic chorio-retinitis in children and young adults are recurrences of congenital infections, it is likely that the infection had subsided by the time the child was born, leaving, however, small foci of encysted Toxoplasma organisms, some of which are in the retina and may become active at a later age.

Toxocara canis infestation probably or possibly accounted for 15 cases in this series, 10 per' cent. of the total. The patients' ages ranged from 3 to 13 years. Twelve gave a history of contact with dogs, usually puppies, and in those tested the skin test for Toxocara was positive. Toxocara infestation should be suspected in any child with a granulomatous mass in the posterior segment. Eosinophilia is not necessarily present, as this will depend on the severity of the initial infestation and the length of time which has elapsed since it occurred.

Peripheral choroiditis was noted in 5 cases and a further 6 had dense vitreous opacities and possibly had similar peripheral lesions which could not be seen. No history of contact with dogs was elicited in these cases, and although clinically they resembled some of those thought to be due to Toxocara infestation there was no supporting evidence for this diagnosis. No other aetiological factor was discovered.

Four cases presented with a chronic uveitis accompanied by swelling of the optic disc and one of these was thought to be due to sarcoidosis. Sarcoidosis was also thought to be the cause of 2 cases of chronic anterior uveitis.

Six cases were found to have perivascular retinal lesions, but no definite aetiological factor was discovered. There were 4 patients with heterochromic uveitis in the series, and 2 were thought to have metastatic bacterial endophthalmitis, a condition known to occur more frequently in children than in adults.

A possible or probable aetiology or distinct disease entity could be assigned in $76(50 \cdot 2$ per cent.) of the children (Table XIV).

TABLE XIV

Probable Aetiology of Uveitis in 150 Children

\begin{tabular}{l|c|c}
\hline \multicolumn{1}{c|}{ Probable Aetiology } & No. of Cases & Percentage of Total \\
\hline Toxoplasmosis & 31 & $20 \cdot 6$ \\
Toxocara canis & 15 & $10 \cdot 0$ \\
Vasculitis & 6 & $4 \cdot 0$ \\
Herpes simplex & 5 & $3 \cdot 3$ \\
Tuberculosis & 5 & $3 \cdot 3$ \\
Heterochromic uveitis & 4 & $2 \cdot 6$ \\
Sarcoidosis & 4 & $2 \cdot 6$ \\
Sympathetic ophthalmitis & 2 & $1 \cdot 3$ \\
Endophthalmitis & 2 & $1 \cdot 3$ \\
Syphilis (congenital) & 1 & $0 \cdot 6$ \\
Vogt-Koyanagi syndrome & 1 & $0 \cdot 6$ \\
\hline \multicolumn{1}{c|}{ Total } & 76 & $50 \cdot 2$ \\
\hline
\end{tabular}


Summary

The clinical features of uveitis in 150 children and the possible aetiological factors are reviewed.

Uveitis is less common in children than in adults and is more likely to be chronic in character. Chronic anterior uveitis with band-shaped opacities of the cornea and secondary cataract may be associated with juvenile rheumatoid arthritis, but in many cases there was no evidence of rheumatism. There was a marked preponderance of girls among the cases of chronic anterior uveitis.

Toxoplasmosis was thought to be responsible for the uveitis in 20 per cent. of all cases, and was typified by focal chorio-retinitis; in most cases the evidence suggested that the disease was congenital in origin.

Toxocara canis infestation was the probable or possible cause in 10 per cent. of cases. Herpes simplex, tuberculosis, sarcoidosis, and syphilis were each responsible for a few cases, and there were some cases of vasculitis retinae, heterochromic uveitis, and sympathetic ophthalmitis. In half the cases no definite aetiological factor could be found.

I am indebted to the surgical staff of Moorfields Eye Hospital for referring patients to the Uveitis Clinic, to the Department of Pathology of the Institute of Ophthalmology for the pathological studies, to Mr. I. M. Duguid for carrying out the Toxocara skin tests, and to the Department of Medical Illustration for preparing the histogram.

\section{REFERENCES}

Bennett, G. (1955). Brit. J. Ophthal., 39, 727.

Blegvad, O. (1941). Acta ophthal. (Kbh.), 19, 219.

Davis, M. D. (1953). A.M.A. Arch. Ophthal., 50, 443.

Duguid, I. M. (1961). Brit. J. Ophthal., 45, 705, 789.

GuYton, J. S., and Woods, A. C. (1941). Arch. Ophthal. (Chicago), 26, 983.

Hogan, M. J. (1958). Amer. J. Ophthal., 46, 467. (1965). Trans. ophthal. Soc. U.K., 85, 39.

- Zweigart, P. A., and Lewis, A. (1958). A.M.A. Arch. Ophthal., 60, 548.

Kimura, S. J., Hogan, M. J., and Thygeson, P. (1954). Ibid., 51, 80.

MarCheSANI, O. (1949). Albrecht v. Graefes Arch. Ophthal., 149, 69

Perkins, E. S. (1961). "Uveitis and Toxoplasmosis". Churchill, London.

REMKY, H. (1962). "Toxoplasmosis: argumenta et documenta ophthalmologica". Lehmann, Münich.

SCHEPENS, C. L. (1950). Bull. Soc. franç. Ophtal., 63, 113.

Smiley, W. K., May, E., and Bywaters, E. G. L. (1957). Ann. rheum. Dis., 16, 371.

Unger, H.-H., and Schomerus, E. (1954). Klin. Mbl. Augenheilk., 124, 326.

Vesterdal, E., and SURY, B. (1950). Acta ophthal. (Kbh.), 28, 321.

Welch, R. B., Maumenee, A. E., and Wahlen, H. E. (1960). Arch. Ophthal. (Chicago), $64,540$.

Wood, R. M., Ellison, A. C., Kelley, K. C., and Kaufman, H. E. (1965). Ibid., 73, 482.

ZsCheIle, F. P. (1964). Ibid., 71, 645. 